\title{
Moving Along: performance and moving-image as contemporary media of a global circulation of culture
}

\author{
Renata Gaspar \\ Calouste Gulbenkian Foundation, Lisbon, Portugal \\ Flat B, 45 Trafalgar Avenue, London, SE15 6NP, UK \\ contact@renatagaspar.com
}

\section{INTRODUCTION}

This practice-led research project seeks to address the use of New Media in contemporary artistic productions in the field of Performance Art in relation to the current "consumption" of Media in everyday life contexts.

The research will be carried out through the analysis of works and the practical exercise of performances that include pre-recorded image and / or live image, as well as video performances, covering theoretical aspects of Media and Visual Culture, in a critical study supported by ideas from existing discourses on the common "language" and "gestures" that are being produced by the current consumption and contact with the Media. The project will allow establishing points of contact between contemporary social and cultural perspectives on image and sound, and performative notions of space and time, considering the latter as two formally interrelated poles where issues of visuality, aurality, spectatorship, site-specificity and kinaesthetic qualities lay upon.

\section{OBJECTIVES}

The project aims to research social and cultural perspectives in the use of New Media in Performance Art. By looking at contemporary New Media Performance Art productions and at existing social and cultural concepts on visuality and aurality, the research will establish an overview of the current status of Performance Art and the way it looks at public and everyday life.

Some of the questions:

How does mediated image and sound shape the performative environment and affect the live event by alienating and simultaneously engaging the spectator? What social and cultural ideas arise from the possibility of having access to close-ups, other locations and times than the ones physically accessible to the viewer?

Achievements:

Understanding how Performance Art is representative of contemporary cultural tendencies and reflect on how the different layers of information allowed, now at a greater extend, through the vast use of New Media, contribute to a recognised growing tendency of Performance as a trans-disciplinary practice that is, at the same time, recipient and emissary of cultural ideas.

\section{CONTEXT}

A) Words like digital, virtual, telematics, cyberspace, intermediality, multimedia, are all part of a recent and ongoing technological revolution that has invaded, since its very start (with EAT - Experiments in Art and Technology - in 1967) the arts in general, and the Performance Art in particular.

But science, engineering and technology are in constant processes of reshaping themselves, their objects of interest and their working methods, with recurrent surprising outcomes, thus the application of new media technologies within the performing arts has also been following that striking tendency, giving rise to unique ways of technological appropriation, which also represent new modes of networked and participative forms of expression.

Nevertheless, the words and concepts mentioned above follow the current innovative trend and their meaning encounters several varied modulations, depending on how they're employed: they can be subjects or adjectives - this language vulnerability mirrors the artistic activity itself, in the way artists use and manipulate concepts through their practice. Under which light can we then assemble a systematic overview on the use of New Media in contemporary Performance Art? I do argue for a critical and analytical perspective of the basics, which are, nonetheless common to all Media based works - image and sound, not from the traditional aesthetic and compositional cinematic viewpoints (that would only takes us as far as a superlative form of description and comparison) but from a social and cultural contextualization, in order to enable us to grasp the understanding of a practice that is essentially permutable and very fast accommodating the technology available.

B) The research I'm currently holding and the work I've been undertaking with Julian Maynard Smith (Station House Opera) has been devoted to Telematic Theatre, in particular to issues of global dramaturgies, both compositional and technological.

Crucial questions intrinsic to spatial and temporal subjects have been subject of my practice and investigation development. Through the course of this project l've been recognising the need for an intersection of socio-cultural critical possibilities, in the search for new borders of aural-visual artistic interest. 